\title{
INFORME DEL DR. CARLOS R. SILVA MOJICA
}

Señor Dr.

Humberto Correa

Presidente de la Sociedad Colombiana de Obstetricia y Ginecología

Estimado Dr.:

Por medio de la presente quiero informar a Ud. y a los miembros de la Corporación de mis labores como Delegado de la Sociedad Colombiana de Obstetricia y Ginecología ante el I Congreso Panamericano de Hipnología que se reunió en Río de Janeiro en los días 16 a 22 de Julio del presente.

$1^{\circ}$ - Con anterioridad al mencionado congreso visité las ciudades de Sao Paulo (Brasil) y Buenos Aires donde entrevisté distinguidos obstetras e hipnólogos y conocí numerosas clínicas obstétricas, comprobancio un gran interés por la obstetricia sicosomática, la preparación sicoprofiláctica de las embarazadas y la aplicación de métodos hipnosugestivos en el embarazo y en el parto.

$2^{\circ}$ - En Buenos Aires asistí a las primeras jornadas argentinas de Hipnología celebrados los días 8 y 9 de Julio. Formé parte de la Mesa Coordinadora de dicho certamen, presenté un trabajo personal "Concepto de la Hipnosis como Relajación Médica”, y tomé interesantes apuntes sobre Analgesia hipnótica del parto. Fuí invitado también a una mesa redonda a la Sociedd Argentina de Hipnosis Médica e Hipnoanálisis. Fuí nombrado por esta Sociedad Miembro del Comité de Redacción de la Revista "Acta Hipnológica Latino Americana", que es la tribuna de la Confederación Latino Americana de Hipnosis clínica y experimental. Visité numerosos miembros de la Sociedad Argentina de Sicoprofilaxis obstétrica, Juan José Báez, Uranga Imaz, Shawrcz, Shuzt y otros. Estuve observando la organización de sus servicios de sicoprofilaxis, sus sistemas de trabajo y sus estadísticas. Comprobé en aquella ciudad una amplia difusión de la Sicoprofilaxis y asimilé nuevas ideas para implantar en nuestro medio.

$3^{\circ}$ - En el Congreso de Río de Janeiro presidí un Simposio donde se trataron las aplicaciones de la Hipnosis en Obstetricia y Ginecología: náuseas y vómitos del embarazo, analgesia y anestesia obstétrica, inducción del parto, depresiones del puerperio, esterilidad sicogénica, frigidez y dispareunia. Representé a la Sonciedad con un trabajo original sobre "Síndrome Depresivo Emetizante de las embarazadas".

$4^{\circ}$ - Principalmente me llamaron la atención en Río de Janeiro estos hechos: una sólida formación reflexológica en los principales obstetras, un notable perfeccionamiento de la Sicoprofilaxis obstétrica, una amplia aceptación de la Hipnosis, y una marcada tendencia a reforzar la Sicoprofilaxis obstétrica con métodos hipnosugestivos.

$5^{\circ}$ - Las recomendaciones del Congreso fueron las siguientes: 
a) Solicitar al Gobierno la expedición de una ley reglamentaria que limite la práctica de la hipnosis en usos exclusivamente médicos y odontológicos.

b) Introducir en los programas de las facultades de medicina y odontología la enseñanza de la Hipnología.

c) Que las aplicaciones de la hipnosis en medicina y odontología se ciñan a la ética profesional.

d) Que sea estudiada la unificación de la nomenclatura hipnológica.

e) Recomendar a los países representados en este congreso la prohibición de espectáculos de hipnotismo. legal.

f) Prohibir cursos de hipnología dictados por quien no tenga autorización

g) Recomendar a los hipnólogos se abstengan de practicar hipnosis frente a personas ajenas al tratamiento.

h) Recomendar a las entidades hipnológicas obediencia rigurosa a los posculados de ética profesional.

i) Encargar a la Sociedad Brasilera de Hipnología la redacción definitiva y la publicación de estas recomendaciones.

$6^{\circ}$ - El Gobierno del Brasil por decreto No 51.009 del 22 de Julio de 1961 expidió un decreto prohibiendo la hipnosis como espectáculo público o diversión.

$7^{9}$ - Una amplia información sobre estas experiencias la presenté en el III Simposio Colombiano de Sicoprofilaxis Obstétrica, reunido a fines de Julio en Bucaramanga, como también en la Sociedad Colombiana de Obstetricia Sicosomática y próximamente en la Sociedad Colombiana de Hipnología.

$8^{\circ}$ - A nombre de EMESFAO, hice una invitación a un ilustre obstetra de Río de Janeiro, el Dr. Dionisio Cavalheiro, para dictar un curso sobre Obstetricia Sicosomática en Bogotá. El Dr. Cavalheiro vendrá a principios de Noviembre y tratará estos temas: estado actual de reflexología; fundamentos reflexológicos de la hipnosis y métodos hipnosugestivos de analgesia obstétrica.

Sin otro particular, y con la satisfacción de haber representado debidamente en el extranjero a la Sociedad Colombiana de Obstetricia y Ginecología y a Colombia, me es grato suscribirme su s.s. colega y amıgo. 